\title{
Comparison of catechin profiles in human plasma and urine after single dosing and regular intake of green tea (Camellia sinensis)
}

\author{
Shing-Tack Fung, Cyrus K. Ho, Siu-Wai Choi, Wai-Yuen Chung and Iris F. F. Benzie* \\ Department of Health Technology and Informatics, The Hong Kong Polytechnic University, Kowloon, Hong Kong
}

(Submitted 26 March 2012 - Final revision received 22 August 2012 - Accepted 22 August 2012 - First published online 30 October 2012)

\section{Abstract}

Green tea (Camellia sinensis) catechin profiles in plasma and urine following single dosing and regular ingestion of green tea are not clear. We performed a placebo-controlled intervention study with sixteen healthy volunteers to determine changes in total and free catechins after a single dose and following 1 week of twice-daily green tea. Blood and urine samples were collected before (fasting) and after (60 and $120 \mathrm{~min}$ for blood; 90 and $180 \mathrm{~min}$ for urine) drinking $200 \mathrm{ml}$ of $1.5 \%(\mathrm{w} / \mathrm{v})$ green tea or water $(n 8$ each), and fasting samples were again collected after $7 \mathrm{~d}$ of $150 \mathrm{ml}$ of $1 \%(\mathrm{w} / \mathrm{v})$ supplemental green tea or water twice daily. After a 4-week washout, subjects were crossed onto the other treatment and procedures repeated. Plasma results at $1 \mathrm{~h}$ post-ingestion showed elevated $(P<0 \cdot 05)$ mean epigallocatechin gallate (EGCG; 310 (SD 117) nmol/1; all in free form), epigallocatechin (EGC; 192 (SD 67) nmol/1; $30 \%$ free) and epicatechin gallate (ECG; $134(\mathrm{SD} 51) \mathrm{nmol} / 1 ; 75 \%$ free). Fasting plasma after $7 \mathrm{~d}$ of regular intake showed increased $(P<0 \cdot 05)$ EGCG (80 $v$. 15 nmol/1 at baseline) and ECG $(120 v .40 \mathrm{nmol} / \mathrm{l})$, with $\geq 90 \%$ of both in their conjugated forms. Total EGC was $<10$ nmol/1. Post-ingestion conjugation and renal loss of EGC and epicatechin were rapid and high, but were negligible for EGCG and ECG. In the green tea consumed, the content was EGCG > EGC > ECG, and the acute plasma response mirrored this. However, after chronic consumption there was almost no EGC found in fasting plasma, some EGCG was present, but a rather high level of ECG was maintained.

\section{Key words: Green tea: Catechins: Polyphenols: Epigallocatechin gallate: Bioavailability: Biotransformation: Antioxidants}

Green tea (Camellia sinensis) is reported to have various beneficial effects on health ${ }^{(1-3)}$. Green tea is rich (35\% of dry weight) in catechins, a family of polyphenolic flavon-3-ols, and these are the putative bioactive agents ${ }^{(2-4)}$. The major catechin (about 60-70\%) in green tea is epigallocatechin gallate (EGCG), but there are also substantial amounts of epigallocatechin (EGC), epicatechin gallate (ECG) and epicatechin $(\mathrm{EC})^{(2-4)}$. In vitro studies have demonstrated the powerful antioxidant properties of catechins, particularly EGCG ${ }^{(3-6)}$, and human studies have shown that the plasma total antioxidant capacity increases shortly after the ingestion of green tea ${ }^{(3,5,7)}$. However, poor gastrointestinal absorption, rapid phase II metabolism and urinary excretion of conjugated catechins severely limits their bioavailability and, thereby, their biological effects $^{(4,5,8-10)}$. Including the absorption (assessed by their urinary excretion) of ring fission catechin metabolites produced from colonic bacteria increases 'catechin' bioavailability to about $40 \%$ (ranging from $<3$ to $100 \%$ ), but interindividual differences in urinary concentrations of these metabolites are very large, and their physiological relevance is currently unknown $^{(9-15)}$.
In human subjects, a single dose of green tea, tea solids or purified catechins results in an increase in plasma catechins that peaks at $1-2 \mathrm{~h}$ post-ingestion ${ }^{(4,5,8-10,13-17)}$. However, it is not clear if EGC or EGCG is the predominant catechin in plasma shortly following tea ingestion, or if ECG and EC are present. Further, the profile of free and conjugated catechins in plasma and urine in the acute post-absorption phase is not clear. EGCG appears to escape rapid conjugation and excretion, but other catechins in plasma are found mainly in their sulfated and glucuronated forms, and catechins absorbed from a single dose of tea are reportedly removed from plasma within $24 \mathrm{~h}^{(9,10,13,14,17)}$. In addition, it is not yet clear if free or conjugated catechins accumulate in plasma with the regular intake of green tea, or if the baseline (fasting) plasma and urine catechins profiles following the regular intake of green tea are different from those after a single dose. Answering these questions would add to our knowledge of which native or biotransformed components of green tea might be responsible for the health benefits of the regular intake of green tea in the diet, and could help guide dietary recommendations for health promotion. In the present study, acute (up to $2 \mathrm{~h}$ in plasma and $3 \mathrm{~h}$ in urine) responses in total and free

Abbreviations: EC, epicatechin; ECG, epicatechin gallate; EGC, epigallocatechin; EGCG, epigallocatechin gallate.

*Corresponding author: Professor Iris Benzie, email iris.benzie@polyu.edu.hk 
catechins (EGCG, EGC, ECG, EC and catechin) in healthy adults were determined after a single dose of green tea, as well as fasting plasma and urine total and free catechins in the same subjects after $7 \mathrm{~d}$ of twice-daily green tea intake.

\section{Methods and materials}

\section{Study design}

The present study was a placebo-controlled human intervention trial of cross-over design. A total of sixteen (four men, twelve women) healthy, non-obese volunteers aged 35-50 years were recruited. The present study was conducted according to the guidelines laid down in the Declaration of Helsinki and all procedures involving human subjects were approved by the Human Subjects Ethics Sub-committee of The Hong Kong Polytechnic University. Written informed consent was obtained from all subjects. Subjects were non-smokers, free from hypertension, did not take regular medication or antioxidant or vitamin supplements, and had no previous history of serious illness or hospitalisation during the previous 12 months. Volunteers who reported having taken any kind of prescribed medication, including antibiotics, in the previous 3 months were excluded from the study. Subjects were not vegetarians or regular (daily) tea drinkers, though some took tea occasionally. Of the sixteen subjects, fifteen were of Chinese ethnicity and one was Caucasian. Female volunteers were excluded if pregnant, lactating or on hormone replacement therapy. All volunteers provided written informed consent before commencing the study.

\section{Sample collection and treatments}

Each of the sixteen volunteers was allocated non-selectively to a first treatment of tea $(n 8)$ or water $(n 8)$. On day 1 , venous blood (collected into heparinised collection tubes) and urine samples ('spot' urine, collected into plain containers without preservative) were collected before (fasting) and at timed intervals (60 and $120 \mathrm{~min}$ for blood, 90 and $180 \mathrm{~min}$ for urine) after a single dose $(200 \mathrm{ml}$ of $1.5 \%, \mathrm{w} / \mathrm{v})$ of freshly prepared green tea, or the same volume of hot water as the control treatment. In addition, fasting blood and urine samples were collected after 1 week (i.e. on day 8) of regular consumption of green tea $(150 \mathrm{ml}$ of $1 \%(\mathrm{w} / \mathrm{v})$ green tea twice daily, except for the first dose used in the acute study as described above) or the same dose of hot water. After a 4 -week washout period, each subject was crossed over onto the other treatment and the procedures of days 1-8 were repeated.

Subjects were requested to maintain their usual diet throughout the study, except for the two additional cups of tea or water per d. The green tea used (Longjing 'pre-rain' green tea) was kindly provided by the Ying Kee Tea House, Hong Kong. Subjects were provided with cups (with a mark denoting $150 \mathrm{ml}$ volume), a week's supply of tea bags, and instructions on how to prepare and take their tea twice daily. The tea bags were prepared by the investigators and each contained $1.5 \mathrm{~g}$ of Longjing green tea leaves. Volunteers were given verbal and written instructions to add one tea bag to the cup containing freshly boiled water (added to the $150 \mathrm{ml}$ mark), gently agitate the tea bag in the water for $3 \mathrm{~min}$, then remove and discard the tea bag. The volunteers were instructed to drink the freshly prepared tea within $20 \mathrm{~min}$. Compliance was assessed by regular inquiry and by counting returned tea bags at the end of the intervention period: return of $<20 \%$ of tea bags that should have been consumed (i.e. $80 \%$ compliance) was regarded as satisfactory. The investigators performing the laboratory analysis were not informed of the order of treatment for each participant, but the volunteers unavoidably knew when they took tea or water, making this a single-blinded study.

\section{Sample handling, workup, and catechin measurement}

Blood and urine samples were centrifuged ( $3000 \mathrm{~g}$ for $10 \mathrm{~min}$ ) within a few minutes of collection. Plasma and urine samples were sampled and stored at $-80^{\circ} \mathrm{C}$ until thawed (once only) for catechin analysis. The creatinine concentration of each urine sample was measured on the day of collection by a commercial kit method (Biosystems). Urine catechin concentration was standardised to that of creatinine to correct for differences in water content.

Total and free EGCG, EGC, ECG, EC and catechin were measured in plasma and urine samples using HPLC with tandem MS (HPLC-MS/MS), based on published protocols with some modification ${ }^{(13,18)}$. All reagents used were of the highest purity grade available. EGCG, EC, ECG, EGC, catechin and taxifolin (internal standard), ascorbic acid, ammonium acetate, acetonitrile, EDTA disodium salt dihydrate, acetic acid, $\beta$-glucuronidase (type VII-A from Escherichia coli; 5292000 units/g) and sulfatase (type H-1 from Helix pomatia; 24954 units/g) were from Sigma-Aldrich. Methanol, sodium dihydrogen orthophosphate dihydrate and disodium hydrogen phosphate were from BDH. Samples of thawed plasma and urine $(100 \mu \mathrm{l})$ were stabilised by adding $10 \mu \mathrm{l}$ of $10 \% \mathrm{aqu}-$ eous ascorbic acid containing $0 \cdot 1 \%$ EDTA $-\mathrm{Na}_{2} \cdot 2 \mathrm{H}_{2} \mathrm{O}(\mathrm{w} / \mathrm{v})$ and then subjected to enzyme pre-treatment (for measurement of total (conjugated plus free) catechin measurement) by adding $10 \mu \mathrm{l}$ of $\beta$-glucuronidase buffer (containing 240 units in $0 \cdot 1 \mathrm{M}$-aqueous $\mathrm{Na}_{2} \mathrm{HPO}_{4}(\mathrm{pH}$ 6.8) ) and $10 \mu \mathrm{l}$ of sulfatase buffer (containing 20 units in $\mathrm{pH}$ 6.8), after which $25 \mu \mathrm{l}$ of diluent A (2\% aqueous ascorbic acid containing $0 \cdot 1 \%$ EDTA $-\mathrm{Na}_{2} \cdot 2 \mathrm{H}_{2} \mathrm{O}(\mathrm{w} / \mathrm{v})$ in a solution containing $0.4 \mathrm{M}-\mathrm{NaH}_{2} \mathrm{PO}_{4}(\mathrm{pH} 3.6)$, methanol and water in a ratio of 10:10:80, by vol.) and $25 \mu \mathrm{l}$ of internal standard ( $0 \cdot 2 \mu \mathrm{m}$-taxifolin in diluent $\mathrm{A}$ ) were added, and the mixture was incubated at $37^{\circ} \mathrm{C}$ for $45 \mathrm{~min}$. In order to extract catechins and precipitate protein from samples, $250 \mu \mathrm{l}$ chilled methanol was added after samples had been cooling in ice-water for $1 \mathrm{~min}$. The mixtures were then vortexed and returned to the ice-water for $5 \mathrm{~min}$, followed by centrifugation at $4^{\circ} \mathrm{C}, 15000 \mathrm{~g}$ for $10 \mathrm{~min}$. The methanol fraction containing the catechins ( $150 \mu \mathrm{l}$ of the supernatant fraction) was collected and mixed with $100 \mu \mathrm{l} 4.75 \mathrm{~mm}$-aqueous ammonium acetate ( $\mathrm{pH} 4.5$ ) before HPLC-MS/MS analysis. For samples without enzyme treatment (free catechin measurement), $20 \mu \mathrm{l}$ of $0 \cdot 1 \mathrm{M}$-aqueous 
$\mathrm{Na}_{2} \mathrm{HPO}_{4}(\mathrm{pH}$ 6.8) was added instead of $\beta$-glucuronidase and sulfatase buffer solutions, and the incubation at $37^{\circ} \mathrm{C}$ for 45 min was waived.

Free and total EGCG, EGC, ECG, EC and catechin of the test samples and of a typical $1.5 \%(\mathrm{w} / \mathrm{v})$ infusion of green tea were measured using an HPLC system (Agilent 1200 Series, G1311A quaternary pump and G1322A micro vacuum degasser) equipped with a thermostatted well-plate autosampler (G1329A; set at $4^{\circ} \mathrm{C}$ ) linked to a 3200 QTRAP ${ }^{\circledR}$ mass spectrometer (Applied Biosystems/MDS Sciex). MS/MS analysis was performed in negative ion mode with a Turbolonspray ${ }^{\circledR}$ source. Gradient HPLC separations were performed on a Waters Symmetry column $\left(\mathrm{C}_{18} ; 3.5 \mu \mathrm{m} ; 4.6 \mathrm{~mm} \times 150 \mathrm{~mm}\right)$ protected with a Sentry Guard column $\left(\mathrm{C}_{18} ; 5 \mu \mathrm{m}\right.$; $3.9 \mathrm{~mm} \times 20 \mathrm{~mm}$ ). Column temperature was at room temperature $\left(21.5^{\circ} \mathrm{C}\right)$ with mobile phase A $(5 \%$ acetonitrile and $95 \%$ $2 \mathrm{~mm}$-aqueous ammonium acetate ( $/ \mathrm{v}$, adjusted to $\mathrm{pH} 4.5$ with acetic acid)) and mobile phase $\mathrm{B}(95 \%$ acetonitrile and $5 \% 20 \mathrm{~mm}$-aqueous ammonium acetate (v/v, pH 4.5)). Both solutions were filtered through a $0.22 \mu \mathrm{m}$ Millipore filter before use. Gradient HPLC separations were performed, starting with $100 \%$ mobile phase $\mathrm{A}$, and linearly ramping to $90 \%$ $\mathrm{A} / 10 \% \mathrm{~B}$ in $1 \mathrm{~min}$, then to $82 \% \mathrm{~A} / 18 \% \mathrm{~B}$ in another $13.5 \mathrm{~min}$, to $58 \% \mathrm{~A} / 42 \% \mathrm{~B}$ in $3 \mathrm{~min}$, to $20 \% \mathrm{~A} / 80 \% \mathrm{~B}$ in $2.5 \mathrm{~min}$ and finally, by an immediate increase in $0.1 \mathrm{~min}$, to $100 \% \mathrm{~A}$ and keeping this for a $4.9 \mathrm{~min}$ equilibrating period. The flow rate was constant at $0.5 \mathrm{ml} / \mathrm{min}$. The injection volume was $50 \mu \mathrm{l}$. A typical overlay (with all detecting channels) chromatogram is shown in Fig. 1. In the mass spectrometer, calibration, control and sample data were obtained by multiple reactions monitoring acquisition with standard precursor ions ([M-H] $\left.]^{-}, \mathrm{Q} 1\right)$ and product ions (Q3) (Table 1). All the product ions were quantified using a dwell time of $150 \mathrm{~ms} /$ channel with unit mass resolution for Q1 and Q3 (Table 1). The source parameters were set as follows: curtain gas $\left(\mathrm{N}_{2}\right), 12 \cdot 0$ psi (pounds per square inch); collision gas $\left(\mathrm{N}_{2}\right)$, medium; ionspray voltage, $-4500 \mathrm{~V}$; temperature, $650^{\circ} \mathrm{C}$; ion

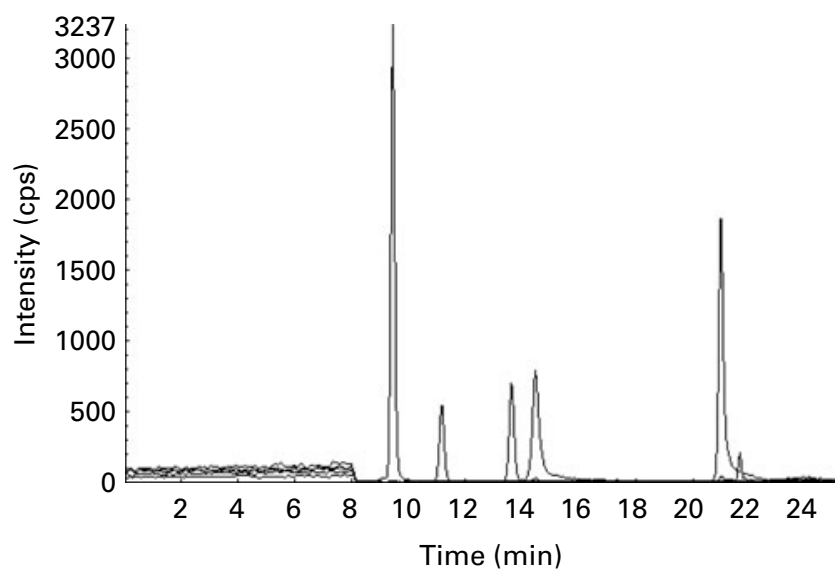

Fig. 1. Typical catechin overlay chromatogram showing elution patterns of epigallocatechin ( $9.4 \mathrm{~min})$, catechin $(11.2 \mathrm{~min})$, epicatechin (13.6 min), epigallocatechin gallate $(14.4 \mathrm{~min})$, epicatechin gallate $(21.0 \mathrm{~min})$ and the internal standard $(21.6 \mathrm{~min})$. For details of $\mathrm{m} / \mathrm{z}$, see Table 1 . Eluates were diverted to waste for the first $8 \mathrm{~min}$. source gas 1 (air), 40.0 psi; ion source gas 2 (air), $40 \cdot 0$ psi; interface heater, on. The parameters for the optimised compound were: declustering potential, $-50.0 \mathrm{~V}$; entrance potential, $-4.0 \mathrm{~V}$; collision energy, $-30 \cdot 0 \mathrm{eV}$; collision cell entrance potential, $22.0 \mathrm{~V}$; collision cell exit potential, $-1 \cdot 0 \mathrm{~V}$. All data were acquired and manually processed by Analyst ${ }^{\circledR}$ Software 1.4.2 (AB Sciex). The limit of detection was determined, using the same HPLC-MS/MS conditions as for the test samples, by direct injection of each methanolic catechin pure solution and the concentration that gave three times the signal:noise ratio was taken as the limit of detection. The limit of detection was determined from the chromatogram by the Analyst software, which determines which region contains the peak and the noise based on maximum intensities in each selection, subtracts the average background signal intensity from the background and divides the subtracted signal by the peak-to-peak noise level. The concentration that gave ten times the signal:noise ratio was taken as the limit of quantification. Using this HPLC-MS/MS method, we found limits of quantification (in nmol/l) of: EGCG, $3.6 \mathrm{nmol} / \mathrm{l}$; EGC, $7.3 \mathrm{nmol} / \mathrm{l}$; EC, $58.3 \mathrm{nmol} / \mathrm{l}$; ECG, $1.8 \mathrm{nmol} / 1$; catechin, $58 \cdot 3$. Catechin concentrations were calculated by corresponding peak area ratios (standard/internal standard) compared with the external standard and using the calibration curves generated by injecting 0.78 to $25.0 \mu \mathrm{mol} / 1$ for catechin, EC, EGCG and ECG, and 1.56 to $50.0 \mu \mathrm{mol} / 1$ for EGC in plasma-based calibration, and 1.56 to $50.0 \mu \mathrm{mol} / 1$ for catechin, EC, EGCG and ECG, and 12.5 to $400 \cdot 0 \mu \mathrm{mol} / \mathrm{l}$ for EGC in urine-based calibration

\section{Statistical analysis}

Statistical analysis was carried out using GraphPad Prism 5 (GraphPad Software). The normality of data was analysed with the Kolmogorov-Smirnov test. Data with a normal distribution were analysed using paired $t$ tests and repeatedmeasures ANOVA with Tukey's post hoc test for comparing differences between two and three groups, respectively. Skewed data were analysed using the Wilcoxon matchedpairs signed rank test and the Friedman test with the Bonferroni post hoc test. A $P$ value (two-sided) of $<0.05$ was regarded as statistically significant. For ease of comparison, only the within-treatment results for tea are shown; however, in statistical analysis the comparisons were also made across treatments (i.e. tea $v$. water).

\section{Results}

The catechin content of the typical $1.5 \%(\mathrm{w} / \mathrm{v})$ infusion of Longjing pre-rain green tea and the calculated content of the infusions used for the acute and daily supplement are shown in Table 2 .

Plasma catechins after single dosing and $7 \mathrm{~d}$ of green tea supplementation are presented in Table 3 . In plasma at $1 \mathrm{~h}$ post-ingestion, EGCG, EGC, ECG and EC were significantly increased $(P<0.05)$ compared with baseline (fasting) and with the timed-matched values after ingestion of water. Plasma total catechins averaged about $650 \mathrm{nmol} / 1$ at $1 \mathrm{~h}$ 
Table 1. Standard precursor ions (Q1) and product ions (Q3) for catechins*

\begin{tabular}{|c|c|c|c|c|}
\hline Compound & Full name & Precursor ion $[\mathrm{M}-\mathrm{H}]^{-} \mathrm{Q} 1$ at $\mathrm{m} / \mathrm{z}$ & Product ion Q3 at $\mathrm{m} / \mathrm{z}$ & Retention time in HPLC system (min) \\
\hline EGC & (-)-Epigallocatechin & $305 \cdot 2$ & $125 \cdot 1$ & $9 \cdot 4$ \\
\hline C & (-)-Catechin & 289.2 & $109 \cdot 1$ & $11 \cdot 2$ \\
\hline EC & (-)-Epicatechin & 289.2 & $109 \cdot 1$ & $13 \cdot \overline{6}$ \\
\hline EGCG & (-)-Epigallocatechin gallate & 457.4 & $169 \cdot 1$ & 14.4 \\
\hline ECG & (-)-Epicatechin gallate & $441 \cdot 2$ & $169 \cdot 0$ & $21 \cdot 0$ \\
\hline Internal standard & Taxifolin & $303 \cdot 2$ & $125 \cdot 0$ & $21 \cdot 6$ \\
\hline
\end{tabular}

*The conditions for the mass spectrometer were: curtain gas $\left(\mathrm{N}_{2}\right), 12.0$ pounds per square inch (psi); collision gas ( $\left.\mathrm{N}_{2}\right)$, medium; ionspray voltage, $-4500 \mathrm{~V}$; temperature, $650^{\circ} \mathrm{C}$; ion source gas 1 (air), $40.0 \mathrm{psi}$; ion source gas 2 (air), $40.0 \mathrm{psi}$; interface heater, on; declustering potential, $-50.0 \mathrm{~V}$; entrance potential, $-4.0 \mathrm{~V}$; collision energy, $-30.0 \mathrm{eV}$; collision cell entrance potential, $22.0 \mathrm{~V}$; collision cell exit potential, $-1.0 \mathrm{~V}$.

post-ingestion, representing a 10-fold increase over fasting values. The largest contributor $(40-50 \%)$ to the increase seen $1 \mathrm{~h}$ post-ingestion was EGCG, all of which was in the free form. The next largest increase was in EGC (which comprised about $25-30 \%$ of total catechins in post-ingestion plasma), most of which $(70-80 \%)$ was in the conjugated form, followed by ECG (20\% of total catechins in post-ingestion plasma), most of which (75\%) was in the free form. Only four of the sixteen subjects had detectable EC in $1 \mathrm{~h}$ postingestion plasma, and this was all in the conjugated form. No catechin was detected in post-ingestion plasma. The $2 \mathrm{~h}$ post-ingestion levels of EGCG, EGC and ECG remained elevated $(P<0.05)$, with EGCG remaining predominantly in the free form at $2 \mathrm{~h}$, but a larger fraction of ECG was in the conjugated form (about $50 \% \mathrm{v}$. about $25 \%$ at $1 \mathrm{~h}$ ). In fasting samples collected after $7 \mathrm{~d}$ of green tea supplementation, a significant $(P<0.05)$ increase in fasting plasma EGCG was seen (from about $16 \mathrm{nmol} / \mathrm{l}$ at baseline and with placebo treatment, to about $80 \mathrm{nmol} / 1$ after $7 \mathrm{~d}$ of green tea treatment). However, the increase was modest in comparison with the marked rise in EGCG seen in the acute study (peak concentration about $300 \mathrm{nmol} / \mathrm{l}$ ), and almost $90 \%$ of the EGCG was in the conjugated form, in contrast to the acute post-ingestion increase, which was all in the free form. Total ECG concentrations after $7 \mathrm{~d}$ supplementation with green tea had increased 3-fold (from about 40 to about $120 \mathrm{nmol} / 1 ; P<0.05$ ), but ECG was also predominantly $(>95 \%)$ in the conjugated form. Total EGC was very low (and undetectable in eleven of the sixteen subjects), with no free EGC found, and no EC or catechin was found in day 8 fasting plasma

Urine results are presented in Table 4. Following a single dose of tea, the concentration of EGC in urine was markedly higher $(P<0.05)$ in the $90 \mathrm{~min}$ samples, and a similar level of EGC excretion was seen in the 180 min urine samples. Significantly $(P<0.05)$ increased EC was also found in the 90 and 180 min urines, but interindividual variation was very wide. Very small, though statistically significant $(P<0 \cdot 05)$, increases in conjugated EGCG and ECG were seen in urine at 90 or 120 min post-ingestion. In day 8 fasting urines, the predominant catechin present was conjugated EGC (at concentrations that were markedly higher than in day 1 fasting urines and in $7 \mathrm{~d}$ urines after placebo treatment; $P<0 \cdot 05)$. EC in urine after $7 \mathrm{~d}$ of green tea intake showed very high interindividual variation and was not statistically significantly different $(P>0.05)$ from baseline or after placebo. The day 8 fasting urine concentrations of total EGCG and ECG were higher $(P<0.05)$ than on day 1 , but the amounts were very small (averaging $\leq 5 \mathrm{nmol} / \mathrm{l}$ )

In regard to the amount of each catechin in the green tea ingested in the acute study and each day for $7 \mathrm{~d}$, the rank order was: ECGC ( $214 \mu \mathrm{mol}$ ingested) $>$ EGC $(114 \mu \mathrm{mol}$ ingested $)>$ ECG $=\mathrm{EC}$ (about $45 \mu \mathrm{mol}$ ingested) $>$ catechin $(8 \mu \mathrm{mol}$ ingested).

\section{Discussion}

There is growing evidence of the health benefits of a regular intake of green tea, which include hypotensive, anti-carcinogenic, detoxification, anti-inflammatory, lipid-lowering and anti-obesity effects ${ }^{(1-5,19-25)}$. To date, the catechins have attracted most interest in the study of green tea and health, though it is noted that other components of green tea, including caffeine, vitamin $\mathrm{C}$, theanine, saponins and $\gamma$-aminobutyric acid, may contribute to health promotion ${ }^{(24-26)}$. Furthermore, there is growing awareness that colonic metabolites of catechins can be absorbed in relatively large amounts ${ }^{(10-12)}$, and that at least some of the many

Table 2. Catechin content of a typical $1.5 \%(\mathrm{w} / \mathrm{v})$ infusion of the tea (Longjin 'pre-rain' green tea; Camellia sinensis) used in the acute study, with the calculated catechin content of the doses used for the acute intake and daily supplement

\begin{tabular}{lccc}
\hline & $\begin{array}{c}\text { Concentration in } 1.5 \% \\
(\mathrm{w} / \mathrm{v}) \text { infusion used in acute study } \\
(\mu \mathrm{mol} / \mathrm{l})\end{array}$ & $\begin{array}{c}\text { Estimated dose } \\
(\mu \mathrm{mol}) \text { ingested in the acute study } \\
\text { (in 200 ml of } 1.5 \%(\mathrm{w} / \mathrm{v}) \text { green tea) }\end{array}$ & $\begin{array}{c}\text { Estimated daily dose } \\
(\mu \mathrm{mol}) \text { in the } 7 \mathrm{~d} \text { study } \\
\text { (in 2 } 2 \times 150 \mathrm{ml} \text { of } 1 \%(\mathrm{w} / \mathrm{v}) \mathrm{green} \text { tea) }\end{array}$ \\
\hline Total catechins & 2130 & 426 & 426 \\
EGCG & 1070 & 214 & 214 \\
EGC & 570 & 114 & 114 \\
ECG & 230 & 46 & 46 \\
EC & 220 & 44 & 44 \\
C & 40 & 8 & 8 \\
\hline
\end{tabular}

EGCG, epigallocatechin gallate; EGC, epigallocatechin; ECG, epicatechin gallate; EC, epicatechin; C, catechin. 
Table 3. Plasma catechins ( $\mathrm{nmol} / \mathrm{l})$ after a single dose of $200 \mathrm{ml}$ of $1 \%(\mathrm{w} / \mathrm{v})$ green tea and following $7 \mathrm{~d}$ of regular intake of $2 \times 150 \mathrm{ml}$ of $1 \%(\mathrm{w} / \mathrm{v}) \mathrm{green}$ tea $($ Camellia sinensis) (Mean values and standard deviations, medians and ranges; $n$ 16)

\begin{tabular}{|c|c|c|c|c|c|c|c|c|c|c|c|c|c|}
\hline & \multicolumn{3}{|c|}{ EGCG } & \multicolumn{3}{|c|}{ EGC } & \multicolumn{3}{|c|}{ ECG } & \multicolumn{2}{|c|}{ EC } & \multicolumn{2}{|c|}{ C } \\
\hline & Total & Free & $\%$ Free & Total & Free & $\%$ Free & Total & Free & $\%$ Free & Total & Free & Total & Free \\
\hline \multicolumn{14}{|l|}{ Fasting } \\
\hline Mean & 16 & 3 & 25 & None & None & - & 41 & 5 & About 10 & 5 & None & None & - \\
\hline SD & 13 & 8 & & detected & detected & & 28 & 10 & & 18 & detected & detected & \\
\hline Median & 14 & $<1$ & & & & & 32 & 3 & & $<1$ & & & \\
\hline Range & $0-47$ & $0-33$ & & & & & $5-89$ & $0-40$ & & $0-73$ & & & \\
\hline \multicolumn{14}{|c|}{$+1 \mathrm{~h}$ post-ingestion } \\
\hline Mean & $310^{*}$ & $310^{*}$ & 100 & $192^{*}$ & $56^{*}$ & About 30 & $134^{*}$ & $102^{*}$ & About 75 & $16^{*}$ & 4 & None & - \\
\hline SD & 117 & 117 & & 67 & 288 & & 51 & 37 & & 29 & 15 & detected & \\
\hline Median & 293 & 293 & & 169 & 50 & & 122 & 90 & & $<1$ & $<1$ & & \\
\hline Range & $124-535$ & $124-535$ & & $99-327$ & $25-132$ & & $47-230$ & $61-196$ & & $0-75$ & $0-62$ & & \\
\hline \multicolumn{14}{|c|}{$+2 \mathrm{~h}$ post-ingestion } \\
\hline Mean & $226^{*}$ & $213^{*}$ & 100 & $169^{*}$ & $32^{*}$ & About 20 & $138^{\star}$ & $73^{*}$ & About 50 & 12 & None & None & - \\
\hline $\mathrm{SD}$ & 97 & 117 & & 98 & 13 & & 61 & 37 & & 35 & detected & detected & \\
\hline Median & 205 & 168 & & 148 & 32 & & 127 & 59 & & $<1$ & & & \\
\hline Range & $99-597$ & $99-597$ & & $96-472$ & $12-51$ & & $46-250$ & $41-182$ & & $0-130$ & & & \\
\hline \multicolumn{14}{|c|}{ Fasting after $7 d$ of twice-daily tea } \\
\hline Mean & $80^{*}$ & $10^{*}$ & $<13$ & $5^{*}$ & None & - & $116^{*}$ & 6 & $<5$ & None & None & None & - \\
\hline SD & 33 & 8 & & 9 & detected & & 55 & 4 & & detected & detected & detected & \\
\hline Median & 77 & 7 & & $<1$ & & & 126 & 6 & & & & & \\
\hline Range & $28-132$ & $0-30$ & & $0-29$ & & & $37-212$ & $1-12$ & & & & & \\
\hline
\end{tabular}

EGCG, epigallocatechin gallate; EGC, epigallocatechin; ECG, epicatechin gallate; EC, epicatechin; C, catechin.

${ }^{*}$ Mean value was significantly different from that at baseline and from the time-matched placebo result $(P<0.05)$. 
Table 4. Urine total catechins ( $\mathrm{nmol} / \mathrm{mmol}$ creatinine) after a single dose and after $7 \mathrm{~d}$ of twice-daily intake of green tea (Camellia sinensis)

(Mean values and standard deviations, medians and ranges; $n$ 16)

\begin{tabular}{|c|c|c|c|c|c|c|}
\hline Catechin & Day 1 fasting & $+90 \min$ & $+180 \min$ & Day 7 fasting & $\begin{array}{l}\text { Day } 1-7 \text { change } \\
\text { in fasting levels }\end{array}$ & Comment \\
\hline \multicolumn{7}{|l|}{ EGCG } \\
\hline Mean & 1 & $7^{*}$ & $8^{*}$ & $5^{*}$ & $+4 \cdot 6^{*}$ & \multirow{4}{*}{$\begin{array}{l}\text { Very small amounts of conjugated EGCG in urine; very small } \\
\text { but significant }(P<0.05) \text { increase in total EGCG with } \\
\text { single and regular intake }\end{array}$} \\
\hline SD & 1 & 6 & 6 & 5 & 4.7 & \\
\hline Median & $<1$ & 7 & 8 & 4 & $+3 \cdot 1$ & \\
\hline Range & $0-3$ & $0-23$ & $0-23$ & $0-19$ & 0 to $+19 \cdot 4$ & \\
\hline \multicolumn{7}{|l|}{ EGC } \\
\hline Mean & 11 & $2977^{*}$ & $2649^{\star}$ & $216^{*}$ & $+206^{*}$ & \multirow{4}{*}{$\begin{array}{l}\text { Highly variable interindividual response; small amounts of free } \\
\text { EGC detected }(<5 \% \text { of total); significant }(P<0.05) \text { increases } \\
\text { in total EGC with single and regular intake }\end{array}$} \\
\hline SD & 22 & 2792 & 1379 & 190 & 191 & \\
\hline Median & 3 & 2306 & 3219 & 154 & +151 & \\
\hline Range & $0-87$ & $319-12389$ & $313-4111$ & $5-586$ & +20 to +586 & \\
\hline \multicolumn{7}{|l|}{ ECG } \\
\hline Mean & 2 & $5^{\star}$ & $6^{*}$ & $4^{*}$ & $+2 \cdot 2^{*}$ & \multirow{4}{*}{$\begin{array}{l}\text { Very small amounts of conjugated ECG in urine; very small but } \\
\text { significant }(P<0.05) \text { increases in total ECG with single and regular intake }\end{array}$} \\
\hline SD & 2 & 3 & 3 & 2 & 2.5 & \\
\hline Median & 2 & 5 & 6 & 4 & $+1 \cdot 7$ & \\
\hline Range & $0-5$ & $1-14$ & $2-17$ & $<1-10$ & -2 to +8 & \\
\hline \multicolumn{7}{|l|}{ EC } \\
\hline Mean & 20 & $967^{*}$ & $711^{*}$ & 49 & 29 & \multirow{4}{*}{$\begin{array}{l}\text { Highly variable interindividual response; some free } \mathrm{EC}(<5 \%) \\
\text { in some subjects; significant }(P<0.05) \text { increases in total EC } \\
\text { following single dose but not regular intake }\end{array}$} \\
\hline SD & 56 & 846 & 641 & 51 & 42 & \\
\hline Median & 0 & 838 & 540 & 33 & +22 & \\
\hline Range & $0-227$ & $0-3031$ & $0-2458$ & $0-192$ & -35 to +130 & \\
\hline
\end{tabular}

EGCG, epigallocatechin gallate; EGC, epigallocatechin; ECG, epicatechin gallate; EC, epicatechin.

* Mean value was significantly different from that at baseline and from the time-matched placebo result $(P<0.05)$ 
microbiological-derived phenolic metabolites detected in human plasma and urine have biological activity in vitro ${ }^{(27)}$. The identity of the flavan-3-ol-metabolising microbes and the bioactivity of the actual conjugated forms of microbial metabolites found in plasma are not yet known, and further study is needed in this important area to elucidate the potentially important biological role of microbial-mediated catabolism of polyphenols in tea, coffee, wine and berries ${ }^{(14,27-29)}$.

Bioavailability of green tea catechins in their 'native' form (i.e. not as colonic metabolites) is low, the type and form (native or biotransformed) of catechin(s) responsible for the health benefits of green tea are not yet confirmed, and it is not known if health-related effects are due to recurring 'waves' of short-term effects of freshly absorbed catechins or catechin metabolites, or to more 'chronic' effects of catechins (or their metabolites) that have accumulated with regular intake. It is also unclear if health-related effects are due to the antioxidant or the putative pro-oxidant activities of green tea polyphenols ${ }^{(21,22)}$. Polyphenols could act via different mechanisms, such as carcinogen inactivation, altering gene expression, or modulating intracellular signalling cascades and redox switches involving, for example, NF- $\mathrm{B}$, mitogenactivated protein (MAP) kinases or nuclear factor erythroid 2-related factor $2(\mathrm{Nrf} 2)^{(22,27,30-32)}$

The present study investigated and compared the catechin profiles in plasma and urine following a single dose and after 1 week of supplementation with green tea. Results showed that $1-2 \mathrm{~h}$ after a single dose of green tea ingestion there was a marked increase in plasma EGCG, and the increase was all in free EGCG. Plasma EGC and ECG also increased significantly after ingestion. For ECG, the increase was mostly due to free ECG. For EGC, most of the increase was in the conjugated form. Urine collected at 1.5 and $3 \mathrm{~h}$ post-ingestion contained markedly increased amounts of conjugated EGC and conjugated EC, but EGCG and ECG were almost undetectable. Assuming 3 litres of circulating plasma, the $1 \mathrm{~h}$ EGCG concentration in plasma $(310 \mathrm{nmol} / \mathrm{l})$ represents $0 \cdot 14 \%$ of the dose ingested, all was in the free form and negligible amounts were entering the urine. For EGC, the $1 \mathrm{~h}$ concentration of $192 \mathrm{nmol} / 1$ (total) represents $0.17 \%$ of the dose, but only $30 \%$ of this $(0.05 \%$ of the amount ingested) was in the free form, and early renal loss of EGC was high. For ECG, the $1 \mathrm{~h}$ concentration $(134 \mathrm{nmol} / \mathrm{l})$ represents $0.3 \%$ of the dose, about $75 \%$ of this was circulating in the free form, and, as with EGCG, negligible amounts were found in urine at up to $3 \mathrm{~h}$ post-ingestion. The $1 \mathrm{~h}$ EC concentration $(16 \mathrm{nmol} / \mathrm{l})$ represents $<0.05 \%$ of the dose ingested, none was in the free form, and, as for EGC, renal loss was rapid. Based on these figures, the 'efficiency' of absorption from a single dose of green tea with subsequent release into the plasma ('bioavailability') for catechins in the free form was highest for EGCG in absolute terms, but in relative terms a higher fraction of ingested ECG was circulating in post-ingestion plasma. The actual fraction of the dose absorbed will be higher if partitioning into extracellular fluids and tissue uptake occurs quickly after ingestion. In terms of conjugated catechins, about $0.12 \%$ of the ingested dose of EGC was conjugated and circulating in the plasma at $1 \mathrm{~h}$ post-ingestion, the figure for EC was $<0.03 \%$, and that for ECG was $0.075 \%$. However, despite renal loss, the $2 \mathrm{~h}$ plasma levels of EGC and EC were similar to the $1 \mathrm{~h}$ levels. This suggests ongoing absorption (and conjugation) of ECG and EC. Interestingly, the plasma levels of EGCG and ECG were also similar at $2 \mathrm{~h}$ to those at $1 \mathrm{~h}$ post-ingestion, despite negligible renal loss of these catechins. However, if EGC and EC continue to be absorbed between 1 and $2 \mathrm{~h}$ post-ingestion, this is likely to be the case for ECGC and ECG also. Why, then, did plasma levels of EGCG and EC remain steady between 1 and $2 \mathrm{~h}$ post-ingestion? One reason could be biliary excretion; another could be tissue uptake.

There is some evidence from animal and cell culture studies of tissue uptake of catechins. In pregnant rats fed green tea extract, EGCG was taken up more readily into fetal tissues than other catechins in the extract ${ }^{(33)}$, and EGCG was found in the prostate and liver of CF-1 mice fed pure EGCG ${ }^{(34)}$. A concentration-dependent uptake of EGCG into cultured human colon cancer cells has also been reported ${ }^{(34)}$. Human data are scarce, but in prostate cancer patients $(n 8)$ who took six cups of green tea daily for up to 6 weeks before radical prostatectomy, EGCG in its methylated and free forms was found in prostate tissue ${ }^{(35)}$. ECG was also present in prostate tissue, but in lower amounts ${ }^{(35)}$. Notably, the authors found that most of the EGCG and other green tea polyphenols found intracellularly were not conjugated, though some was in the methylated form ${ }^{(35)}$. Therefore, it appears that unconjugated EGCG and ECG can enter cells. Unfortunately, due to technical difficulties, we did not measure methylated forms of catechins in plasma or urine. However, no methylated EGCG or ECG has been found in metabolite profiling studies on human subjects ${ }^{(9,10,36)}$. Methylated EGCG was found in cultured prostate cancer cells treated with EGCG, but it was reported that methylation lowered the inhibitory effects of EGCG on cell growth and NF- $\mathrm{BB}$ activation, and lowered induction of apoptosis in the cancer cells ${ }^{(35)}$. These data imply that methylation of EGCG is an intracellular event that 'traps' and lowers the bioactivity of EGCG. It is not known if this applies also to ECG, the other catechin that escapes conjugation and rapid renal excretion.

From the acute response data presented here it appears that EGCG and ECG are absorbed more readily than other catechins, entering the plasma soon after ingestion, and escaping rapid conjugation and renal loss. This makes them more 'bioavailable' for tissue uptake. In contrast, EGC and EC, which are also absorbed quite quickly after ingestion, are rapidly conjugated and excreted in the urine, making them less 'bioavailable', although their absorption and conjugation appear to continue for at least $2 \mathrm{~h}$ after tea ingestion, maintaining their plasma levels during this period despite high renal loss. With regular intake of green tea, EGCG and ECG in fasting plasma accumulate to some extent, reaching levels 3- to 5-fold higher than baseline; the fasting plasma EGCG concentration after $7 \mathrm{~d}$ of twice-daily intake was only about $25 \%$ of that reached $1 \mathrm{~h}$ after a cup of tea was ingested (about $300 \mathrm{nmol} / \mathrm{l}$ ), while the ECG concentration was similar to the peak plasma level reached in the acute study (about $130 \mathrm{nmol} / \mathrm{l})$, despite there being much less ECG in the tea. 
Almost no EGC was found in post-supplementation fasting plasma (though a small amount was found in urine), despite the significant increase seen in the acute study and the EGC content of the tea being double that of ECG. Notably, the accumulated EGCG and ECG were predominantly in their conjugated forms, but only trace amounts of EGCG and ECG were found in post-supplementation fasting urine. Therefore, it is not simply conjugation that determines renal loss. The fate of conjugated EGCG and ECG is not known, but may be biliary excretion. In contrast to EGCG and ECG, there was no accumulation of EGC and EC in plasma with the regular intake of green tea, most likely because of rapid conjugation and renal excretion of each ingested dose; however, as previously reported ${ }^{(35)}$ and confirmed in the present study, some EGC and EC are present in fasting urine after chronic intake of green tea.

There have been several previous studies that have investigated acute post-absorption changes ('bioavailability') in plasma catechins after ingestion of green tea or green tea extract ingestion ${ }^{(8-13,15-18,36,37)}$. Study design and methodology have differed between studies, most were small $(n<10)$, and conjugated and free catechins were often not differentiated, but bioavailability figures across all the studies were low, although a 3.5-fold increase in bioavailability was reported when tea polyphenols were taken in the fasting state and without co-ingestion of food ${ }^{(37)}$. Despite the study differences, the results of acute response studies are consistent in that they show post-ingestion 'waves' of increased amounts of catechins in the plasma. The present study confirms that more EGCG is absorbed in absolute terms from green tea, but that ECG is relatively better absorbed, that both EGCG and ECG escape rapid conjugation and renal loss, and that with regular intake of green tea the levels of EGCG and ECG are significantly increased in fasting plasma, with quite high levels of ECG maintained, although the increase is due mainly to the conjugated forms of EGCG and ECG and is modest for EGCG. However, despite conjugation there are negligible amounts of EGCG and ECG in urine. In contrast, EGC and EC are rapidly conjugated and excreted, and we saw no evidence that they accumulate in plasma with regular tea drinking.

The present study has several limitations. We did not measure the methylated forms of catechins. Methylated EC and EGC sulfates and glucuronides have been found in plasma and urine, but no methylated EGCG or ECG has been reported ${ }^{(9,10,36)}$. Also, we have not yet studied changes in biomarkers that could be affected by acute or chronic green tea intake, such as gene activation, lipids, or inflammatory or oxidative stress biomarkers. We will address some of these issues in follow-up studies.

In conclusion, significant increases in plasma EGCG, EGC and ECG were seen in the acute study. Post-ingestion conjugation and renal loss of EGC and EC were rapid and high, but were negligible for EGCG and ECG. In the green tea consumed, the content of EGCG $>$ EGC $>$ ECG, and the acute plasma response mirrored this. However, after chronic consumption there was almost no EGC found in fasting plasma, some EGCG was present, but a rather high level of ECG was maintained.

\section{Acknowledgements}

The present study was financially supported by The Hong Kong Polytechnic University. The green tea used was kindly supplied by Ying Kee Tea House, Hong Kong. The contribution of each author to the manuscript and work described was as follows: C. K. H., S.-W. C. and I. F. F. B. were responsible for the planning of the study; S.-T. F. and W.-Y. C. performed the HPLC-MS/MS work, and were responsible for catechin data acquisition and statistical analysis; C. K. H. and S.-W. C. recruited and liaised with volunteers, prepared the supplement, and were responsible for sample collection, creatinine measurements and initial sample workup; I. F. F. B. was responsible for the ethics application, treatment allocation, and overall supervision of the work; all authors contributed to the interpretation of results and preparation of the final manuscript. The authors have no conflicts of interest.

\section{References}

1. Wang QM, Gong QY, Yan JJ, et al. (2010) Association between green tea intake and coronary artery disease in a Chinese population. Circ J 74, 294-300.

2. Khan N \& Mukhtar H (2007) Tea polyphenols for health promotion. Life Sci 81, 519-533.

3. Yang CS, Lambert JD \& Sang S (2009) Antioxidative and anticarcinogenic activities of tea polyphenols. Arch Toxicol 83, $11-21$.

4. Williamson G \& Manach C (2005) Bioavailability and bioefficacy of polyphenols in humans II. Review of 93 intervention studies. Am J Clin Nutr 81, 243S-255S.

5. Higdon JV \& Frei B (2003) Tea catechins and polyphenols: health effects, metabolism, and antioxidant functions. Crit Rev Food Sci Nutr 43, 89-143.

6. Benzie IFF \& Szeto YT (1999) Total antioxidant capacity of teas by the ferric reducing/antioxidant power (FRAP) assay. J Agric Food Chem 47, 633-637.

7. Benzie IFF, Szeto YT, Tomlinson B, et al. (1999) Consumption of green tea causes rapid increase in plasma antioxidant power in humans. Nutr Cancer 34, 83-87.

8. Lee MJ, Maliakal P, Chen L, et al. (2002) Pharmacokinetics of tea catechins after ingestion of green tea and (-)-epigallocatechin-3-gallate by humans: formation of different metabolites and individual variability. Cancer Epidemiol Biomark Prev 11, 1025-1032.

9. Stalmach A, Troufflard S, Serafini M, et al. (2009) Absorption, metabolism and excretion of Choladi green tea flavan-3-ols by humans. Mol Nutr Food Res 53, S44-S53.

10. Del Rio D, Calani L, Cordero C, et al. (2010) Bioavailability and catabolism of green tea flavan-3-ols in humans. Nutrition 26, 1110-1116.

11. Roowi S, Stalmach A, Mullen W, et al. (2010) Green tea flavan-3-ols: colonic degradation and urinary excretion of catabolites by humans. J Agric Food Chem 58, 1296-1304.

12. Calani L, Del Rio D, Callegari L, et al. (2012) Updated bioavailability and $48 \mathrm{~h}$ excretion profile of flavan-3-ols from green tea in humans. Int J Food Sci Nutr 63, 513-521.

13. Yang C, Chen L, Lee MJ, et al. (1998) Blood and urine levels of tea catechins after ingestion of different amounts of green tea by human volunteers. Cancer Epidemiol Biomarkers Prev 7, 351-354.

14. Russell W \& Duthie G (2011) Plant secondary metabolites and gut health: the case for phenolic acids. Proc Nutr Soc 70, 389-396. 
15. Chow HH, Cai Y, Hakim IA, et al. (2003) Pharmacokinetics and safety of green tea polyphenols after multiple-dose administration of epigallocatechin gallate and Polyphenon $\mathrm{E}$ in healthy individuals. Clin Cancer Res 9, 3312-3319.

16. Müller N, Ellinger S, Alteheld B, et al. (2010) Bolus ingestion of white and green tea increases the concentration of several flavon-3-ols in plasma, but does not affect markers of oxidative stress in healthy non-smokers. Mol Nutr Food Res 54, 1636-1645.

17. Renouf M, Guy P, Marmet C, et al. (2011) Plasma appearance and correlation between coffee and green tea metabolites in human subjects. Br J Nutr 104, 1635-1640.

18. Cordero C, Canale F, Del Rio D, et al. (2009) Identification, quantitation, and method validation for flavan-3-ols in fermented ready-to-drink teas from the Italian market using HPLC-UV/DAD and LC-MS/MS. J Sep Sci 32, 3643-3651.

19. Han KC, Wong WC \& Benzie IFF (2011) Genoprotective effects of green tea (Camellia sinensis) in humans: results of a controlled supplementation trial. Br J Nutr 105, 171-179.

20. Jochmann N, Baumann G \& Stangl V (2008) Green tea and cardiovascular disease: from molecular targets towards human health. Curr Opin Clin Nutr Metab Care 11, $758-765$.

21. Lambert JD \& Elias RJ (2010) The antioxidant and prooxidant activities of green tea polyphenols: a role in cancer prevention. Arch Biochem Biophys 50, 66-72.

22. Serafini M, Del Rio D, N'Dri YD, et al. (2011) Health benefits of tea. In Herbal Medicine: Biomolecular and Clinical Aspects, 2nd ed., pp. 239-262 [IFF Benzie and S WachtelGalor, editors]. Boca Raton, FL: CRC Press Taylor and Francis Group.

23. Brown AL, Lane J, Coverly J, et al. (2008) Effects of dietary supplementation with green tea polyphenol epigallocatechin-3-gallate on insulin resistance and associated metabolic risk factors: randomized trial. Br J Nutr 101, 886-894.

24. Westerterp-Plantenga MS (2010) Green tea catechins, caffeine and body-weight regulation. Physiol Behav 100, $42-46$.

25. Nikaidou S, Ishizuka M, Maeda Y, et al. (2005) Effect of components of green tea extracts, caffeine and catechins on hepatic drug metabolizing enzyme activities and mutagenic transformation of carcinogens. Jpn J Vet Res 52, 185-192.
26. ITO EN (2012) Major components and health benefits of green tea. http://www.itoen.co.jp/eng/allabout_greentea/ components_benefit/index.html (accessed August 2012).

27. Monagas M, Urpi-Sarda M, Sánchez-Patán F, et al. (2010) Insights into the metabolism and microbial transformation of dietary flavon-3-ols and the bioactivity of their metabolites. Food Funct 1, 233-253.

28. Del Rio D, Borges G \& Crozier A (2010) Berry flavonoids and phenolics: bioavailability and evidence of protective effects. Br J Nutr 104, Suppl. 3, S67-S90.

29. Williamson G \& Clifford MN (2010) Colonic metabolites of berry polyphenols: the missing link to biological activity? Br J Nutr 104, Suppl. 3, S48-S66.

30. Benzie IFF \& Wachtel-Galor S (2010) Vegetarian diets and public health: biomarker and redox connections. Antiox Redox Signal 13, 1575-1591.

31. Hou Z, Lambert JD, Chin K, et al. (2004) Effects of tea polyphenols on signal transduction pathways related to cancer chemoprevention. Mutat Res 555, 3-19.

32. Fraga CS \& Oteiza PI (2011) Dietary flavonoids: role of (-)epicatechin and related procyanidins in cell signaling. Free Radic Biol Med 51, 813-823.

33. Chu KO, Wang CC, Chu CY, et al. (2007) Uptake and distribution of catechins in fetal organs following in utero exposure in rats. Hum Reprod 22, 280-287.

34. Lambert JD, Lee MJ, Diamond L, et al. (2006) Dosedependent levels of epigallocatechin-3-gallate in human colon cancer cells and mouse plasma and tissues. Drug Metab Dispos 34, 8-11.

35. Wang P, Aronson WJ, Huang M, et al. (2010) Green tea polyphenols and metabolites in prostatectomy tissue: implications for cancer prevention. Cancer Prev Res 3, 985-993.

36. Sang S, Lee MJ, Yang I, et al. (2008) Human urinary metabolite profile of tea polyphenols analyzed by liquid chromatography/electrospray ionization tandem mass spectrometry with data-dependent acquisition. Rapid Comm Mass Spectrom 22, 1567-1578.

37. Chow HH, Hakin IA, Vining DR, et al. (2005) Effects of dosing condition on the oral bioavailability of green tea catechins after single-dose administration of Polyphenon E in healthy individuals. Clin Cancer Res 11, 4627-4633. 